\title{
Assessment of practice of prescription writing before and after teaching among interns in Rural Medical College, Loni
}

\author{
Narwane Sandeep $\mathbf{P}^{1}$, Kharde Anup L ${ }^{2 *}$, Kharde Rashmi Bhaskarrao ${ }^{3}$ \\ ${ }^{\mathbf{1}}$ Associate Professor, ${ }^{\mathbf{2}, \mathbf{3}}$ Assistant Professor, ${ }^{\mathbf{1 , 3}}$ Dept. of Pharmacology, ${ }^{\mathbf{2}}$ Dept. of Community Medicine, Rural Medical College, Loni, \\ Maharashtra, India
}

*Corresponding Author: Kharde Anup L

Email: dranup.kharde@gmail.com

\begin{abstract}
Introduction: The present study aims to assess the practice of prescription writing before and after a teaching intervention among interns. Materials and Methods: This longitudinal study was conducted in the Department of Pharmacology, Rural Medical College, Loni. Interns undergoing Internship training programme were included in the study. They were instructed to write a prescription for a common ailment i.e., a patient with throat infection, in a given prescription blank page. The prescriptions were collected before the session of "Prescription Writing" of the Internship training programme, including the above mentioned case as example. After the teaching session was over, the interns were instructed to write the same prescription in light of training received.

Results: The number of interns prescribing the required medicine i.e, antitussives increased statistically. There was also statistically significant reduction in the number of interns who prescribed the unwanted medication i.e, the antimicrobial agents. There was significant increase in number of interns who wrote prescription with date, Generic name, Doctor details, patients details, Instruction to patient, rationality. There was statistically significant reduction in the number of interns prescribing antibiotic use, average number of drugs and over prescription.

Conclusion: Interns tend to make errors during prescription writing indicating a poor retention of undergraduate teaching in Pharmacotherapeutics. An intervention in the form of internship training programme for training of prescription training is essential for reviving their knowledge and skills of prescription writing.
\end{abstract}

Keywords: Training program, Prescription writing, Rational drug prescribing, Interns, Antimicrobial use.

\section{Introduction}

According to World Health Organisation, name and address of the prescriber, date of prescription, name and strength of the drug, dosage form and total amount, prescriber's initials or signature, name, age and address of the patient are the important for an ideal prescription. It takes care that the prescription does not go wrong. Prescription writing encompasses skilful application of knowledge of both drugs and disease. ${ }^{1}$ After the completion of MBBS degree, the period of Internship involves medical apprenticeship under the supervision of a Registered Medical Practitioners. During this period, the intern learns both clinical skill of performing procedures as well as management of patients with the help of good clinical judgement. They are junior most doctors working under supervision in a tertiary care hospital. $^{2}$

Under prescribing, overprescribing, inappropriate prescribing, irrational prescribing and prescribing errors are various types of unsuccessful prescribing. ${ }^{3}$ A medication error is any preventable event which may lead to inappropriate medication use or harm to a patient. The number of medication errors reported to Food and Drug Administration (FDA) has crossed the figure of 95,000. ${ }^{4}$ The errors in Prescription may result due to many causes and these can originate from individual as well as organizational factors. ${ }^{5}$ These can be classified as prescribing errors or new prescribing errors. ${ }^{6}$ The causes of a wrong prescription include not only selection of the wrong drug, dose, route of administration, and frequency or duration of treatment, but also evasion of due consideration to characteristics of individual patient or co-existing treatments. Inadequate consideration to potential harm by the given drug also leads to wrong prescription. ${ }^{7}$ Therefore, Prescribing is a complex and high-risk intervention. To inculcate safe prescribing among medical students and interns at the level of an institution, they should be made conscious regarding inclusion of both cognitive and decision-making steps before actually writing of a prescription. The Prescribing errors should be studied, analysed and discussed at individual, team as well as organisational level. ${ }^{8}$ The doctors become confident and competent in prescribing through targeted education programmes. $^{9-13}$

Therefore the present study was aimed to assess the practice of prescription writing before and after a teaching intervention among interns.

\section{Materials and Methods}

The present study was conducted in the Department of Pharmacology in collaboration with Department of Community Medicine, Rural Medical College, Loni. It was a longitudinal study clubbed with Internship training programme. The study was initiated after approval from the Institutional Ethics Committee. All participants were instructed to write a prescription for a common ailment i.e., a patient with throat infection, in a given prescription blank page. The prescriptions were collected before the session of "Prescription Writing" of the Internship training programme, including the above mentioned case as example. After the teaching session was over, the interns were instructed to write the same prescription in light of training received. 


\section{Results}

Seventy three interns were recruited in the study.

Table 1: Number of drugs prescribed before and after teaching prescription writing

\begin{tabular}{|l|l|c|c|c|}
\hline \multicolumn{1}{|c|}{ Type of Medicine } & \multicolumn{1}{|c|}{ Drugs prescribed } & Pre test & Post test & P value* $^{*}$ \\
\hline Anti tussives & Codiene & 44 & 62 & $0.0011^{\#}$ \\
\hline & Chlorpheniramine maleate & 10 & 7 & \\
\hline Antimicrobial agents & Azithromycin & 38 & 28 & 0.1342 \\
\hline & Amoxicillin & 5 & 1 & 0.209 \\
\hline & Amoxicillin and Clavulanic acid & 18 & 3 & $0.0006^{\#}$ \\
\hline & Erythromycin & 2 & 0 & 0.4966 \\
\hline & Total antimicrobial agents & 63 & 32 & $<0.0001^{\#}$ \\
\hline Others & Gargles & 23 & 28 & 0.4877 \\
\hline & Ranitidine & 16 & 10 & 0.2793 \\
\hline & Paracetamol & 14 & 10 & 0.5036 \\
\hline Total Participants & & 73 & 73 & \\
\hline
\end{tabular}

*Fissure's exact test, ${ }^{\#} \mathrm{P}<0.05$

Table 1 shows the number of drugs prescribed before and after the teaching session by the interns. The number of drugs prescribed increased for Codiene (from 44 to 62) and gargles (from 23 to 28), while the number decreased for Chlorpheniramine meleate (from 10 to 7), Azithromycin (38 to 28), Amoxicillin (5 to 1), Amoxicillin-Clavulanic acid (from 18 to 3), Erythromycin (2 to 0 ) and ranitidine (16 to 10). There was statistically significant increase in the antitussives $(\mathrm{P}=0.011$, Fissure's exact test $)$, while there was significant reduction in antimicrobial agents $(\mathrm{P}<0.0001$, Fissure's exact test $)$.

Table 2: Prescription parameters before and after teaching prescription writing

\begin{tabular}{|l|c|c|c|}
\hline \multicolumn{1}{|c|}{ Parameter } & Pre-test (\%) & Post-test (\%) & $\begin{array}{c}\text { P value } \\
\text { (Fisher's Exact Test) }\end{array}$ \\
\hline Date & $52(71.2 \%)$ & $65(89 \%)$ & $0.0119^{*}$ \\
\hline Drug in capital & $1(1.4 \%)$ & $3(4.1 \%)$ & 0.6198 \\
\hline Generic name & $54(74 \%)$ & $67(91.8 \%)$ & $0.0075^{*}$ \\
\hline Brand name & $30(41 \%))$ & $10(13.7 \%)$ & $0.0003^{*}$ \\
\hline Doctor detail & $49(67 \%)$ & $63(86.3 \%)$ & $0.0103^{*}$ \\
\hline Patient detail & $52(71.2 \%)$ & $67(91.8)$ & $0.0024^{*}$ \\
\hline Dosage form & $70(95.9)$ & $71(97.3 \%)$ & 1.0000 \\
\hline Dose & $64(87.7 \%)$ & $70(95.9 \%)$ & 0.1292 \\
\hline Instruction to patient & $6(8.2 \%)$ & $65(89 \%)$ & $<0.0001^{*}$ \\
\hline Rational yes/no & $5(6.8 \%)$ & $57(78 \%)$ & $<0.0001^{*}$ \\
\hline Antibiotic use & $66(90.4 \%)$ & $30(41 \%)$ & $<0.0001^{*}$ \\
\hline Injectable & 0 & 0 & $<0.0001^{*}$ (Unpaired t test) \\
\hline $\begin{array}{l}\text { Average number of drug } \\
\text { prescribed }\end{array}$ & $2.56 \pm 0.62$ & $1.95 \pm 0.97$ & $0.0006^{*}$ \\
\hline Under prescription & 0 & 0 & \\
\hline Over prescription & $56(76.7 \%)$ & $35(48)$ & \\
\hline
\end{tabular}

*P value less than 0.05

As seen in table no. 2, There was statistically significant increase in the number of interns prescribing with date $(\mathrm{P}=0.011)$, Generic name $(\mathrm{P}=0.0075)$, Doctor details $(\mathrm{P}=0.01)$, patients details $(\mathrm{P}=0.002)$, Instruction to patient $(\mathrm{P}<0.0001)$, rationality $(\mathrm{P}<0.0001$, Fissure's exact test $)$. There was reduction in the number of interns prescribing antibiotic use $(\mathrm{P}<0.0001$, Fissure's exact test $)$ and average number of drugs $(\mathrm{P}<0.0001$, Unpaired $\mathrm{t}$ test $)$ and over prescription $(\mathrm{P}=0.0006$, Fissure's exact test)

\section{Discussion}

In the present study the existing knowledge of students regarding the prescription writing for common ailment as well as effect of teaching of prescription writing was assessed. The number of interns prescribing the required medicine i.e., antitussives increased statistically. There was also statistically significant reduction in the number of interns who prescribed the unwanted medication i.e, the antimicrobial agents.

Our study found significant increase in number of interns who wrote prescription with date, Generic name, Doctor details, patients details, Instruction to patient, rationality. There was statistically significant reduction in 
the number of interns prescribing antibiotic use, average number of drugs and over prescription.

In a study by Chaudhari et al, the awareness regarding the rational use of medicines among the interns was not satisfactory. ${ }^{14}$ Desai et al, in his study observed that the training of clinical pharmacology and rational therapeutics conducted during undergraduate course is not retained during internship. ${ }^{15}$ Similar findings were observed in the present study. Venkatesan $M$ reported perception of improved skill among interns after a training session. ${ }^{16}$ Chaudhari et al and Gelal A et al reported improvement in awareness about rational use of medicine with incorporation of the basic concepts of prescribing during the medical training of the newly passed medical graduates ${ }^{14,17}$ and medical students. ${ }^{11,12}$ Ajemigbitse reported reduction in errors of prescription among doctors on providing prescription education and feedback. ${ }^{18}$ A significant reduction in the medication errors was also found in our study which supports the finding of the above mentioned studies.

\section{Conclusion}

Interns tend to make errors during prescription writing indicating a poor retention of undergraduate teaching in Pharmacotherapeutics. An intervention in the form of internship training programme for training of prescription training is essential for reviving their knowledge and skills of prescription writing.

\section{Acknowledgement}

The authors are thankful to the coordinators of Internship training programme.

\section{Source of Funding}

None.

\section{Conflict of Interest}

None.

\section{References}

1. Babar HS, Hussain S, Maqsood Z, Dad AH, Khan M, Rahman AA, et al. Adherence to prescription format and compliance with WHO core prescribing indicators. J Pharma Sci Res. 2014;6(4):195-9.

2. Oshikoya KA, Senbanjo IO, Amole OO. Interns' knowledge of clinical pharmacology and therapeutics after undergraduate and on-going internship training in Nigeria: a pilot study. BMC Med Educ. 2009;9:50.

3. Aronson JK. A prescription for better prescribing. Br J Clin Pharmacol. 2006;61(5):487-91.
4. FDA. Avoiding Medication Mistakes. http://www.fda.gov/ForConsumers/Consumer Updates/ucm048644.htm. (Accessed on 2018 Jan 24).

5. Dean B, Schachter M, Vincent C, Barber N. Causes of prescribing errors in hospital inpatients: a prospective study. Lancet. 2002;359(4):1373-8.

6. Coombes DI, Stowasser AD, Coombes AJ, Mitchellet C. Why do interns make prescribing errors? A qualitative study. Med $J$ Aust. 2008;188(2):89-94.

7. Velo GP, Minuzl P. Medication errors: prescribing faults and prescription errors. Br J Clin Pharmacol. 2009;67:(6):624-8.

8. Patrício PK, Alves BAN, Arenales GN, Queluz KTT. Teaching the rational use of medicines to medical students: aqualitative research. BMC Med Educ. 2012;12:56.

9. Heaton A, Webb DJ, Maxwell SRJ. Undergraduate preparation for prescribing: the views of 2413 UK medical students and recent graduates. Br J Clin Pharmacol. 2008;66(1):128-34.

10. Scobie SD, Lawson M, Cavell G, Taylor K, Jackson SHD, Roberts TE. Meeting the challenge of prescribing andadministering medicines safely: structured teaching and assessment for final year medical students. Med Educ. 2003;37:434-7.

11. Garbutt JM, DeFer TM, Highstein G, McNaughton C, Milligan P, Fraser VF. Safe prescribing: an educational intervention for medical students. Teach Learn Med. 2006;18:244-50.

12. Langford N, Martin U, Kendall M, Ferner R. Medical errors. Medical schools can teach safe drug prescribing and administration. BMJ 2001;322:142-4.

13. Vollebregt JA, Metz JC, de Haan M, Richir MC, Hugtenburg JG, De Vries TP. Curriculum development in pharmacotherapy: testing the ability of preclinical medical students to learn therapeutic problem solving in a randomized controlled trial. Br J Clin Pharmacol. 2006;61:345-51.

14. Chaudhari VL, Mali SN, Dawari AV, Nishandar TB. Awareness about rational use of medicines among fresh Bachelor of Medicine and Bachelor of Surgery graduates. $J$ Educ Health Promot. 2017;6:94

15. Desai MK, Panchal JR, Shah S, Iyer G. Evaluation of impact of teaching clinical pharmacology and rational therapeutics to medical undergraduates and interns. Int J Appl Basic Med Res. 2016;6:205-10.

16. Venkatesan M, Dongre AR, Ganapathy K. Evaluation of skillbased training program on rational drug treatment for medical interns. J Family Med Prim Care. 2017;6:832-5.

17. Gelal A, Gumustekin M, Arici MA, Gidener S. Rational pharmacotherapy training for fourth-year medical students. Indian J Pharmacol. 2013;45:4-8.

18. Ajemigbitse AA, Omole MK, Erhun WO. Effect of providing feedback and prescribing education on prescription writing: An intervention study. Ann Afr Med. 2016;15:1-6.

How to cite this article: Narwane SP, Kharde AL, Kharde RB. Assessment of practice of prescription writing before and after teaching among interns in Rural Medical College, Loni. Indian J Pharm Pharmacol 2020;7(1):1-3. 